\title{
Erratum to: Developing immunity to flight security risk: prospective benefits from considering aviation security as a socio-technical eco-system
}

\author{
Paul McFarlane • Mils Hills
}

Published online: 19 July 2013

(C) Springer Science+Business Media New York 2013

\section{Erratum to: J Transp Secur \\ DOI 10.1007/s12198-013-0113-3}

The original version of this article unfortunately contained a mistake. Captured journal name for reference Hofer and Wetter 2013 was incorrect. The reference entry is now corrected below.

Hofer F, Wetter OE (2012) Operational and human factors issues of new airport security technology — two case studies. J Transp Secur 5(4):277-291

The online version of the original article can be found at http://dx.doi.org/10.1007/s12198-013-0113-3.

P. McFarlane $(\bowtie) \cdot$ M. Hills

Northampton Business School, The University of Northampton,

Cottesbrooke 115, Boughton Green Road, Northampton NN2 7AL, UK

e-mail: paul.mcfarlane@northampton.ac.uk

M. Hills

e-mail: mils.hills@northampton.ac.uk 